\title{
MAPPING OF BIM PROCESS FOR TEACHING LEAN
}

\author{
Shobha Ramalingam ${ }^{1}$
}

\begin{abstract}
Value Stream Mapping (VSM), a Lean tool and Building Information Modelling (BIM) are two contemporary approaches that aim to reduce waste and enhance collaboration in the realization of construction projects. While the principles and practices of both are found to benefit construction processes; there are limited studies that elucidate their synergies and demonstrate the value for teaching lean in construction management programs. VSM visually maps a process and identifies areas for possible improvement. However, it is directly applicable on assembly line operations in a manufacturing industry, an environment which the civil engineering students may not be familiar with, and therefore require experiential learning. To this end, the process of conversion of 2dimensional (2D) design drawings to a 3D building information model of a construction project was foremost captured through VSM technique in an experimental study consisting of 4 student teams. The action learning methodology allowed the teams to generate the current state map, identify wastes in the process and aim for an ideal future state through kaizen efforts and brainstorming sessions. The experiment helped to reinforce the VSM technique in teaching lean and allowed the students to present appropriate opportunities for improvement. Lessons learnt can further act as a stepping stone to benefit professionals in actual practice.
\end{abstract}

\section{KEYWORDS}

Value stream, Process improvement, Lean construction, Action learning, Teaching

\section{INTRODUCTION}

Over the years, the benefit of Lean practices in the construction industry has promoted teaching Lean in the curriculum of construction management programs world-wide. The principles and philosophies of Lean construction are, however, imbibed from the manufacturing industry and as observed by Lobaugh (2008), students with background in civil engineering 'may not be familiar with the manufacturing processes and process flows, let alone the complexities associated with them'. Tsao et al. (2012) identify different methods that Lean educators adopt to facilitate learning for university students

1 Shobha Ramalingam, Ph.D, Assistant Professor, National Institute for Construction Management and Research (NICMAR), Pune, Maharashtra, India. Email: sramalingam@nicmar.ac.in 
including: lectures, tests, assignments, discussions, case-studies, simulations, activityoriented games and field trips. However, researchers including Nofera et al. (2015), Pellicer and Ponz-Tienda (2014) argue that construction engineering and management students, find it difficult to grasp the abstract concepts of 'waste', 'value', 'process', 'conversion' and 'flow' of activities that are analogous to Lean manufacturing. Hence, for effective teaching and learning to take place in construction management programs, experiential learning becomes essential.

To address this concern, a synthetic experiment was conducted through post graduate students with background in civil, mechanical and electrical engineering, for one of the modules of the course on Lean construction at a leading Construction Management Institute in India. The course on Lean construction (3.5 credits), covered most of the key topics on the subject. However, this experiment focussed on integrating Value Stream Mapping (VSM) tool with Building Information Modelling (BIM) process to standardize operations and minimize waste. This was considered necessary as VSM is process oriented and unless students are part of the process, they may not be able to apply the technique in actual practice, as also opined by Lobaugh (2008). The objective of the study was two-fold: to enable the students to 'learn by doing' and to develop leadership and team capacity building skills. The following section provides a brief overview of VSM and BIM, leading to the research question.

\section{LITERATURE REVIEW}

VSM is a powerful diagnostic Lean tool that maps the entire production process graphically, from end-to-end, including flow of material and information to reveal opportunities for minimizing waste, which when improved can induce flow without interruption and enhance productivity (Rother and Shook, 1998). Thus, this tool aims at improving the system, by streamlining individual process steps and identifying areas of waste. In lean manufacturing, any activity that does not add value to the product, is considered as a 'waste' such as: overproduction, waiting, transportation, inappropriate processing, excess inventory, excess motion, defective products and rework (Womack and Jones, 2003). Tapping et al. (2002), proposed a 5 process step for implementing VSM that include: a) determining the appropriate process to improve, b) creating the current state map of the process, c) determining the appropriate metric for improvement, d) creating the future state map of the process, and e) determining improvement methods to bridge the current and future state and initiate action plans.

Some of the recent studies that discuss the application of VSM in construction include: Fontanini et al. (2013) for concrete slab in residential buildings and DantasFilho et al. (2016) for virtual construction process of multi-family housing. All these studies, in common have shown to identify the bottlenecks in the process and have attempted to minimize the wastes. In education, studies by Hadzialic and Weigel (2016), Oberhausen and Plapper (2015) demonstrate the application of VSM through laboratory experiments and student teams. However, there are limited such studies and this triggers further interest to use VSM technique as a demonstrative tool for teaching Lean. 
Li (2015) argues that VSM is not as widely applicable in construction, due to absence of repetitiveness in activities, as in a production line assembly. BIM is a collaborative tool that acts as an interface between design and construction. Modelling is often repetitive in nature. For instance, conversion of 2-dimensional (2D) drawings to 3D models and further on to 4D BIM models for large scale infrastructure projects or highrise buildings, requires sequence of repetitive actions. The benefits of using BIM in design and construction is well documented and include reduced conflicts on site, more coordination amongst the various stakeholders, little delay, minimized re-work and wastage(Eastman et al., 2008). For instance, a study on return-on-investment by Won et al. (2013b), showed a total of 709 errors recorded during design validation of 6 small to medium high rise buildings using BIM. While the Government in developed countries have made BIM usage mandatory in construction projects, it is still not an obligation in developing countries (Kumar and Mukherjee, 2009).However, to aim for BIM maturity in the global market, one need to identify the process improvement steps in BIM. To this end, the research question probed to understand: How does VSM enhance the production of 3Dbuilding information model from 2D design drawings?

\section{RESEARCH SETTING AND METHODOLOGY}

The synthetic experiment was conducted for 3 weeks to model a multi-storey residential building project consisting of $\mathrm{G}+6$ floors. Each floor typically consisted of 5 dwelling units with 2 staircases and a lift shaft. The ground floor comprised of car parking lots and the total area of construction was approximating 20,000 square feet. Four team of students with 3 members each comprising of a civil, mechanical and electrical engineer, were given the task of converting 2D design drawings into 3D BIM in the first week of the experiment using Revit ${ }^{\circledR}$ Architecture and MEP. In the second week, they had to generate 4D BIM from the 3D model using Autodesk Navisworks and the construction sequence of the project in Microsoft Project (MSP). In the third week, they had to optimize the model with respect to cost and time.

VSM implementation followed a structured process (Tapping et al., 2002): In the first step, choosing the value stream, the target state to be improved was logically identified as the first phase of generating 3D model, considering the size of the value stream map, the sequencing relationships of activities, competency of the participants and the total available time. Hence the scope of the study was limited to mapping the 3D BIM process as a single product family. The students were given instructions to produce a $3 \mathrm{D}$ design model, including all the information required for downstream activities (for 4D modelling), without defects and as efficiently as possible in a week's time. The 3D model comprised of five macro-tasks including foundation, framing with roofing, interiors, plumbing and electrical.

In the second step, the current state map was generated using universal symbols, icons, data boxes and different types of arrows. In the third step, Lean metrics and value parameters were determined. Some of the Lean metrics used in this study included: Takt time, cycle time, process time, lead time, defective rate and total value added time, which are defined and explained in the subsequent section. Two output value parameters were 
desired for the study, namely, improved process efficiency and quality. The fourth step involved generating the future state map by minimizing wastes due to inefficiencies, nonvalue added activities, defects, rework, errors and omissions through kaizen efforts and brainstorming sessions. In the fifth step, induced interventions such as providing descriptive know-hows for intermittent processes and action plans to enable producing within the Takt time were implemented.

Two additional members were assigned to monitor each team and track the production process. Data to map the current and future state was collected through stopwatch and photographs. After the current state map was generated, the time required to complete each task was plotted and shown to the teams to understand the steps each team undertook and the resultant variation in activity times. The teams were then explained the Kaizen approach to improve the process, following which they committed an afternoon session on brainstorming areas for improvement, in order to achieve an ideal future state. Four topics were identified to initiate Kaizen discussions that included: productivity, exchange of information across disciplines, rework and optimization techniques. The entire methodology was action-based learning (Stringer, 1999), wherein, each team was involved in the process of solving a practical problem and using a feedback system, evaluated alternatives and implemented an action for future improvement.

\section{RESULTS AND FINDINGS}

The five macro-tasks in the 3D modelling process included foundation, structural framing, architecture and interiors, plumbing and electrical. As a thumb rule, VSM is applicable to process not containing more than 12 tasks (Tapping et al., 2002). Each of these macrotasks represented a work package comprising of 5-6 sub-tasks. For instance, Foundation required levelling and filling, reinforcement layout, concreting, fixing utilities, plinth beam. Structural framing required developing columns, beams including roof slabs, lift shaft, stairwell and head rooms. Interiors included developing internal walls, doors, windows, tiling, parapet and railing.

\section{MAPPING THE CURRENT STATE}

In order to map the current state, the teams foremost discussed to understand the concepts of Takt and cycle time. For instance, with the given 1 week timeline for 3D modelling, and assuming 5 working days and an 8 hour shift, the total given time $=40$ hours $(2400$ minutes) per week. However, with the academic routine, the students could only devote 3 hours per day ( 15 hours $=900$ minutes per week) during the afternoon sessions with an intermittent break of 20 minutes for the experiment. Hence, the total available production time was 800 minutes ( 3 x $5-0.33$ x $5=13.33$ hours) per week. Figure 1 below shows the current state map of the process using predefined icons of VSM. The information recorded in the data box includes the Average cycle times for each task in minutes. 


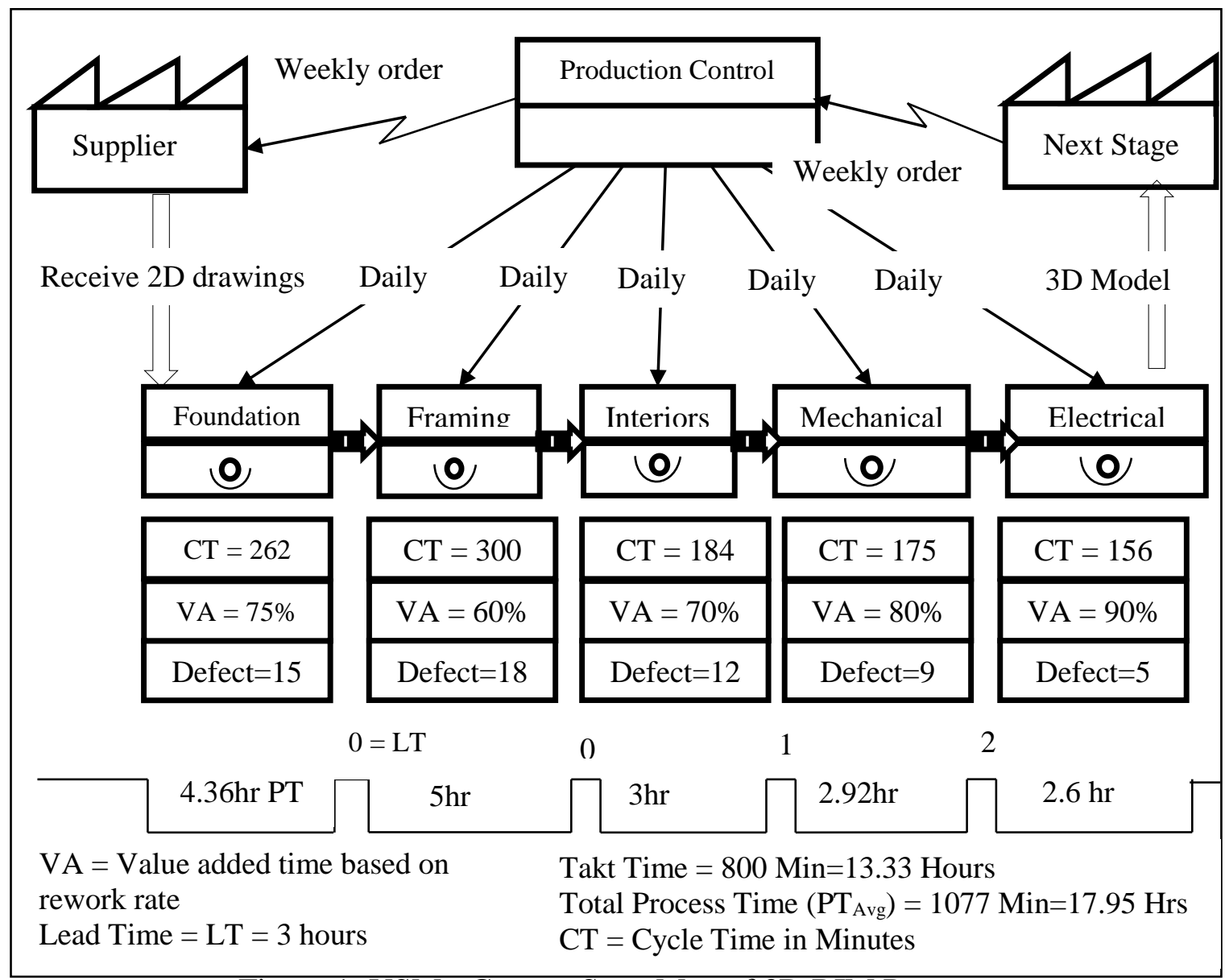

Figure 1: VSM - Current State Map of 3D BIM Process

The current state VSM metrics included:

- Cycle Time (CT) - the duration required to complete the work package. The CT in the current and future state map, is the average of cycle times of the 4 teams.

- Lead Time (LT) - the time elapsed between the task completed and before the start of the next task. LT acts as a buffer to shield downstream activities from upstream variability

- Process time (PT) - the overall cycle time of the sequence of activities.

- Value added (VA) - Value added time

- Takt Time (TT) - the rate at which the 3D model must be built to satisfy the customer demand. Here, Takt time = total available production time, as the demand was $13 \mathrm{D}$ BIM model in 13.33 hours ( 800 minutes) for each team

- Rework rate - Number of times a task was required to be performed in an iterative/rework prone process. This allowed to estimate percentage of VA time.

- Defects - Errors, Omissions leading to rework.

Figure 2 below shows the output of architectural building information model generated with plumbing and electrical services. 


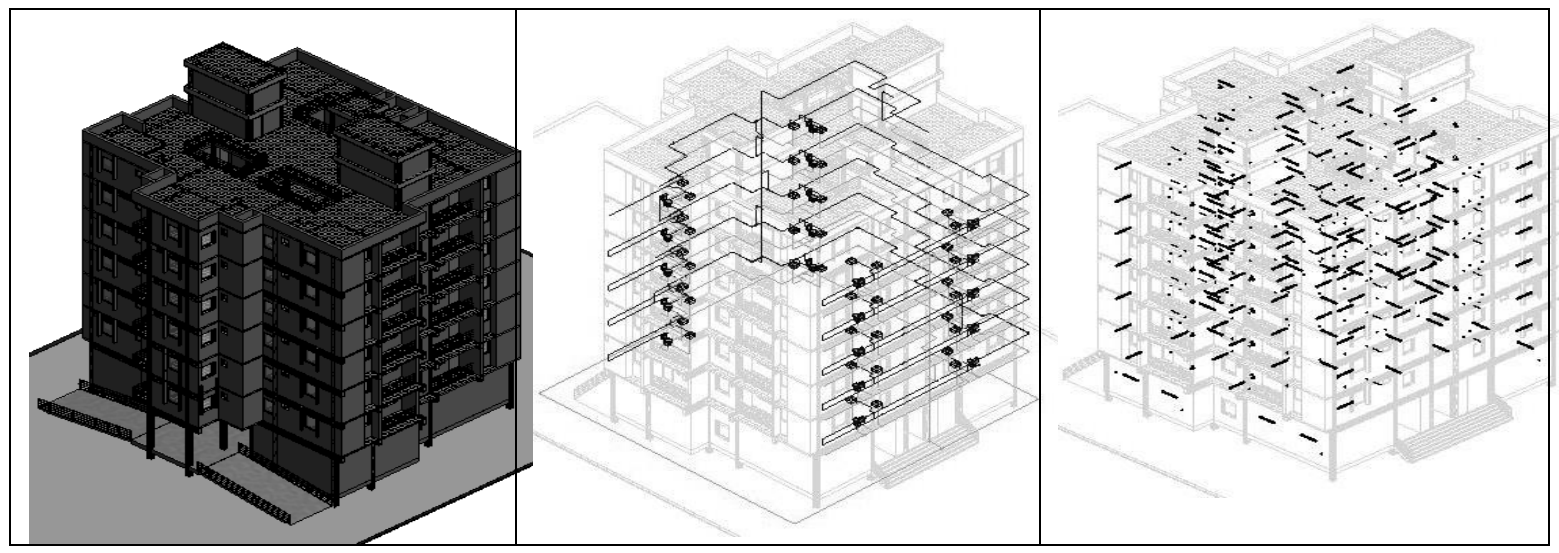

Figure 2: 3D Building Information Model - Architecture, Mechanical and Electrical

Following observations were evident from the current state map. Foremost the teams developed the 3D model in about 17.95 hours (overall production time), exceeding the Takt demand time by nearly 4.6 hours $(34.6 \%$ increase in time). The process time was equal to the cycle times as there was only one resource assigned for each work station. While the civil engineer executed the first three task, the mechanical and the electrical engineer took subsequent turns. The four teams however showed high variability in the production process. For instance, while one team completed the model in 8.4 hours, another team took nearly 25 hours to complete (see Figure $3 \mathrm{a}$ ). Hence, the average cycle time for each task was noted in the current state map. Further, the total lead time available was 3 hours, but only for the second half of the sequencing process that included incorporating Plumbing and Electrical fittings in the model.

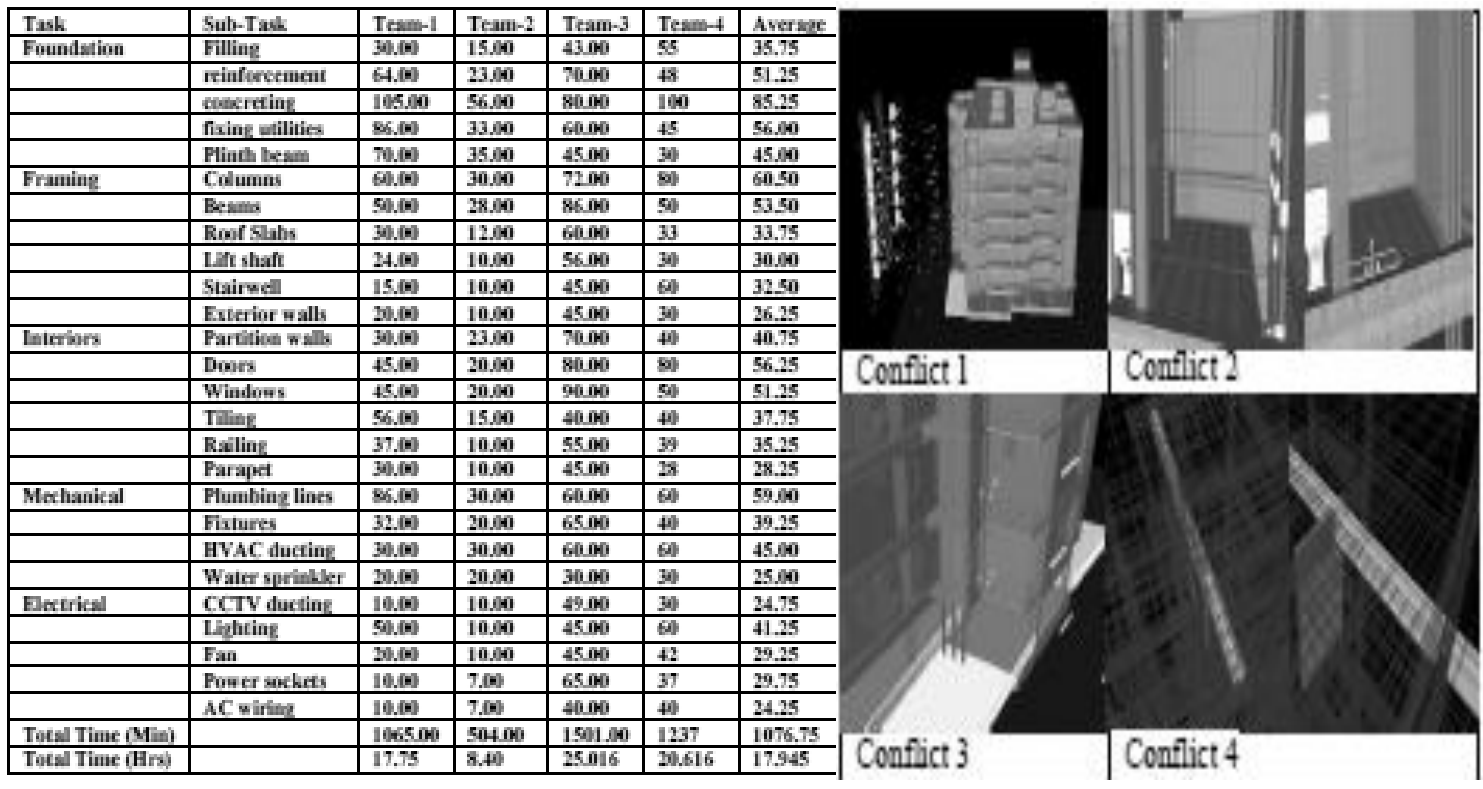

Figure 3a: Time taken by Teams

Figure 3b: Structural Conflicts/Errors 


\section{KAIZEN WORKSHOP AND TEAM REFLECTIONS}

Mapping the value stream, it was evident that more number of defects occurred in the first three process stations leading to rework (refer figure 1). For instance, the amount of value added task during framing was only $60 \%$. This required identifying the cause of rework by the teams through brainstorming session in the Kaizen workshop to identify the bottlenecks as listed below:

- Incomplete information in the 2D drawings/plans - led to waiting period.

- Prior to executing the foundation task, the review time was observed as a nonvalue added but necessary activity.

- Structural clashes in stage 2, such as column in the ramp and staircase (see figure 3b), led to rework. Lack of constructability checks- led to rework. Lack of version control also led to rework. This could also be due to member inexperience.

- Lack of coordination between the actors led to redundant information exchange and discontinuity in the flow. For instance, the initial practice included transmitting information on civil related query only to civil members. This also led to lack of understanding of concurrent processing capabilities.

- Reflecting that the entire sequence was push based rather than being pull-based.

- Expected level of detail varied amongst the actors due to a tendency to over design (over production) and the need for a common guideline was necessary this emphasized the need for standardization of operations. A descriptive knowhow was then developed to minimize this wastage in the future state such as on railings, doors and window details. This reduced the time in the future state by nearly 2 hours for the teams.

- All the teams concurred that the BIM model was heavily front loaded - a situation of excessive processing. Any change in the design due to mechanical or electrical conflict led to remodelling the civil works as well. The teams again voiced the need to work in parallel on a skeleton model, wherein, each actor would develop independently and juxtapose in the end.

- Some of the non-value added tasks (such as the coordinate system) were due to incorrect information or badly formatted information (see figure $3 b$ ).

In summary, the observations identified kaizen burst situations, primarily in the context of information processing (such as waiting time for information, inventory - redundant information, excessive processing and over production of information) where improvements could be made in order to improve efficiency and reduce variability. Further, the interaction with BIM and Lean was also evident, for instance, in achieving user needs; avoiding incomplete information, enhancing visualization and coordination with the actors. This is in concurrence with studies that have explored the benefits of adopting BIM and Lean to improve performance (Sacks et al., 2010).

\section{FUTURE STATE VSM}


In the manufacturing industry, fundamental form of waste is either due to inventory or over-production; while in this exercise, the primary form of waste stemmed from variability - both with respect to cycle times and the quality of output. For instance, the models generated by the teams showed structural clashes between the columns and beams; positioning of columns in staircases and so on. Efficiency and effectiveness are two terms that characterize performance, predictability and variability. The efficiency of a value stream is measured based on the Lead times. In this study, the mechanical and electrical modelling had a waiting time, which induced a buffer in case there was any delay from the upstream activities. However, being on the non-critical path (evident from the schedule generated in MSP), they did not affect the overall production time. Alternatively, the effectiveness of the value stream was calculated by comparing the actual cycle times with the Takt time. Clearly, the actual average cycle time exceeded the takt demand time by $34 \%$ in this study. Hence based on these insights and the value parameters identified earlier in the study, that included 'efficiency' and 'quality', the following recommendations were put forth for future state map:

- Synchronize the output with the Takt demand time to reach an ideal state in future,

- Standardize work procedures to avoid rework such as level of details and types of handrail, staircase etc.

- Restructure work where needed to improve flow and reduce variability and

- Quality control efforts such as through self-checks/checklists. For instance, during kaizen workshop, members created a checklist on constructability parameters to self-validate their model before handing it over to the subsequent modeller. 


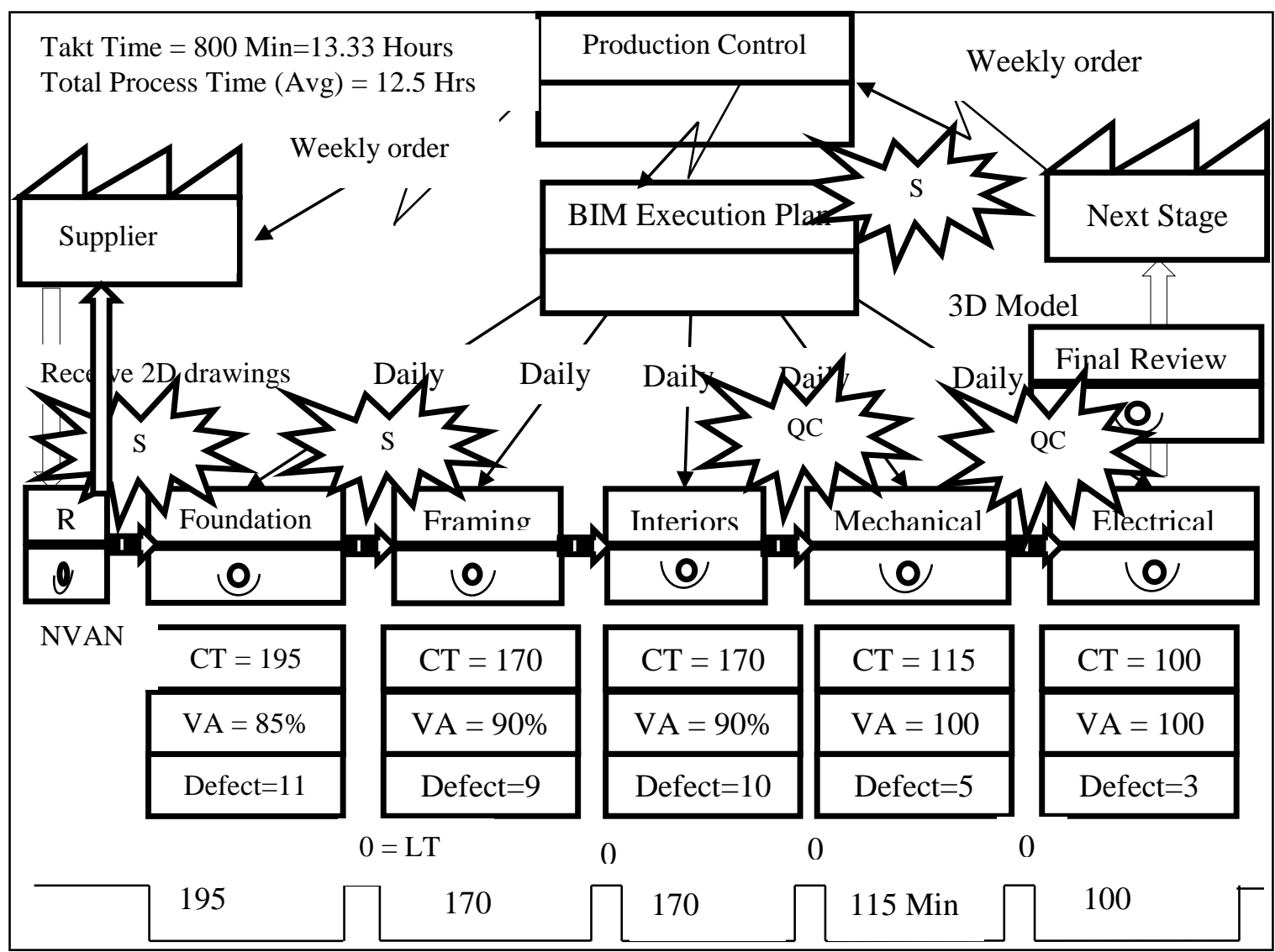

Figure 4: VSM - Future State Map

Figure 4 shows the future state map of the BIM process. The kaizen bursts in the figure shows areas for improvement in the process stations through work restructuring processes which included developing method statement on modelling sequence for stairwells, beams and plumbing ducts and developing a BIM execution plan to act as guiding reference. Such efforts reduced variability and non-value added activities such as waiting for information. Second, Quality control through self-checks were made mandatory during civil, electrical and mechanical hand-overs. Third, as observed earlier, the review stage was a necessary but non-value adding activity. Hence, coordinators were introduced at the beginning and end of the sequence to review the inputs (and seek clarification with the design team where necessary) and facilitate BIM modelling process as well as counter check the product for defects towards the end of the sequence. Though the number of resources increased, the overall cycle times was reduced (to 12.5 hours) by all these measures, which was within the Takt time. Indirect benefits included increased commitment, transparency and coordination amongst the actors apart from learning the VSM technique.

\section{CONCLUSION}

In summary, this study has attempted to demonstrate the value of VSM in BIM process in the design development phase of a construction project through an experimental study. 
The scope of the study was limited to analysing the BIM process for development of 3D model from 2D drawings. The findings were two-fold: foremost, it reinforced the value of the lean tool in identifying and eliminating waste in the BIM process. Also, BIM and Lean are two distinct approaches and this study reinforces their synergies. Second, it helped the members to develop their team building skills.

In specific, mapping the information in the BIM process showed variability in production. Some of the improvement measures included developing method statements, standardizing the process and ensuring quality checks at intermittent levels to minimize rework and waste. Further, enhanced communication such as through a BIM execution plan, aided in establishing pull systems for information and enabled a more efficient flow within the process.

The study has inbuilt limitations due to experimenting in a controlled environment, and the competency level of the participants, who were post graduate students. However, lessons learnt through such action-based-learning experiences can act as a stepping stone for application in practice for professionals. These findings are therefore significant to theory and practice. Future studies could benefit by mapping a comprehensive set of BIM processes and conducting the experiment on live case-situations in projects as well as exploring in relation to upstream and downstream activities.

\section{REFERENCES}

Eastman, C. M., Teicholz, P., Sacks, R., and Liston, K. (2008). BIM handbook: A guide to building information modelling for owners, managers, architects, engineers, contractors, and fabricators, Wiley, Hoboken, N.J.

Brouwer-Hadzialic, L. and Wiegel, V. (2016) Case study: Using value stream mapping in the educational process - How focusing on student actions can help depict the teaching process, International Journal of Six Sigma and Competitive Advantage, 10(1):50

Dantas Filho, J.B.P.; Angelim, B. M.; Barros Neto, J.P. (2016). "Virtual Design and Construction Leaner than Before." In: Proc. 24th Ann. Conf. of the Int'l. Group for Lean Construction, Boston, MA, USA.

Fontanini, P.S.P., de Souza Milano, C., Fujimoto, A., Lintz, R.C.C., Gachet-Barbosa, Jacintho, A.E.P.G.A., Pimentel, L.L., (2013) Concrete Slab Value Stream Mapping of Brazilian Residential Buildings - A Lean Construction Study Case, Advanced Materials Research, 690, 829-834.

Kumar, J. V., \& Mukherjee, M. (2009). Scope of Building Information Modeling (BIM) in India. Journal of Engineering Science and Technology Review, 2(1), 165-169.

Li, Y., (2015). "Value Stream Mapping in Construction and Manufacturing Industry: A Structured Literature Review and Comparative Analysis." Post Graduate Thesis.

Lobaugh, M. (2008) "The value of Value Stream Mapping to Students." AmericanSociety for Engineering Education. Session 2740.

Nofera, W., Abdelhamid, T.S., and Lahouti, A., 2015. Teaching Lean Construction for University Student(s). In: Proc. 23rd Ann. Conf. of the Int'1. Group for Lean Construction. Perth. Australia, pp. 424-433. 
Oberhausen, C. and Plapper, P. (2015) Value Stream Management in the 'Lean Manufacturing Laboratory', Procedia CIRP, 32, 144 - 149.

Pellicer, E.and Ponz-Tienda, J.L. (2014) Teaching and Learning Lean Construction in Spain: A pioneer Experience, Proceedings, IGLC-22, Oslo, Norway.

Rother, M. and Shook, J. (1998) Learning to see: Value stream mapping to create valueand eliminate muda, Brookline, Massachusetts, USA, The Lean Enterprise Institute.

Sacks, R., Koskela, L., Dave, B. A. and Owen, R. (2010). Interaction of lean and building information modelling in construction. Journal of construction engineering and management, 136(9), 968-980.

Stringer, E.T. (1999) Action research, Thousand Oaks, CA: Sage Publications.

Tapping, D., Luyster, T., and Shuker, T. (2002). "Value stream management.'Productivity Press, New York, USA

Tsao, C.C.Y., Alves, T., and Mitropoulos, P. (2012). "Different Perspectives onTeaching Lean Construction." Proc. IGLC-20, July, San Diego, CA.

Womack, J. P. and Jones, D. T. (2003) Lean Thinking: Banish waste and create wealth in your corporation. New York.

Won, J., Lee, G., Dossick, C., and Messner, J. (2013b). Where to focus for successful adoption of building information modeling within organization. Journal ofconstruction engineering and management, 139 (11). 